\title{
Design de notícias no IBGE: as expectativas de designers e jornalistas quanto ao processo
}

\author{
News design at IBGE: designers and journalists expectations about the process
}

\author{
Guilherme da Costa Garcia, Helga Szpiz
}

design de notícias, design da informação, gestão do design, processos de trabalho

Formação, experiência, objetivos e ferramentas moldam a prática dos profissionais envolvidos com a produção de notícias. Nesse processo surgem discrepâncias que podem afetar os resultados, sendo necessário verificar se há desalinhamento nas expectativas dos envolvidos. O Instituto Brasileiro de Geografia e Estatística (IBGE), como instituição com produção frequente de notícias, possui uma equipe de designers e jornalistas dedicados à essa tarefa, integrantes da Coordenação de Comunicação Social (CCS). Foi desenvolvido, em colaboração com a Gerência de Serviços Online (GEON), um sistema gerador de gráficos automatizados a partir de tabelas do SIDRA, sistema para consulta detalhada das pesquisas do IBGE. Além dos gráficos gerados por este sistema, os jornalistas da CCS solicitam aos designers o desenvolvimento de gráficos personalizados para ilustrar as notícias de determinadas pesquisas. Esse artigo apresenta uma investigação sobre a interação entre jornalistas e designers no processo de trabalho, em relação aos motivos que levam à escolha de gráficos automatizados ou personalizados. Para isso com base na literatura sobre design de notícias, demonstrou-se, através de entrevistas, divergências na percepção dos profissionais quanto a esse processo.

news design, information design, design management, work process

Training, experience, goals and tools shape the practice of professionals involved in news production. In this process, discrepancies arise that can affect the results, and it is necessary to check if there is a misalignment in the expectations of those involved. The Brazilian Institute of Geography and Statistics (IBGE), as an institution with a frequent news production, has a team of designers and journalists dedicated to this task, members of the Coordination of Social Communication (CCS). In collaboration with the Online Services Management (GEON), a system for generating automated graphs based on SIDRA tables was developed, a system for detailed consultation of IBGE research. In addition to the graphics generated by this system, CCS journalists asks designers to develop personalized graphics to illustrate news regarding certain researches. This paper presents an investigation of the interaction between journalists and designers throughout the work process, in relation to the reasons that lead to the choice between automated or personalized graphics. Based on the literature on news design, it was demonstrated, through interviews, divergences in the perception of the process by the interviewees.

\section{Introdução}

O Instituto Brasileiro de Geografia e Estatística (IBGE) é o instituto governamental responsável pelo levantamento e disseminação de informações estatísticas e geocientíficas sobre a população e o território brasileiro. É vinculado ao Ministério da Economia, possui quatro

Anais do $10^{\circ} \mathrm{CIDI}$ e $10^{\circ} \mathrm{CONGIC}$

Kelli C.A.S. Smythe, Rafael de Castro Andrade (orgs.)

Sociedade Brasileira de Design da Informação - SBDI

Curitiba | Brasil | 2021
Proceedings of the $10^{\text {th }} \mathrm{CIDI}$ and $10^{\text {th }}$ CONGIC

Kelli C.A.S. Smythe, Rafael de Castro Andrade (orgs.)

Sociedade Brasileira de Design da Informação - SBDI Curitiba | Brazil | 2021 
diretorias e dois órgãos centrais, a saber: Diretoria de Pesquisas (DPE), Diretoria de Geociências (DGC), Diretoria Executiva (DE), Diretoria de Informática (DI), Centro de Documentação e Disseminação de Informações (CDDI) e Escola Nacional de Ciência Estatísticas (ENCE).

A missão do IBGE é "retratar o Brasil com informações necessárias ao conhecimento da sua realidade e ao exercício da cidadania" (IBGE). De acordo com o Plano Estratégico:

A realização dessa missão institucional pressupõe todo um processo que parte das necessidades e demandas por informações existentes na sociedade e governos, passa pela concepção e planejamento das pesquisas, pela coleta de dados em campo, seu armazenamento, a sua análise e validação, até a disseminação dos seus resultados finais para os cidadãos. (IBGE, 2013, p.9)

Com grande produção de notícias, em 2017, a Coordenação de Comunicação Social (CCS) incorporou à sua equipe cinco designers. Naquele momento, suas atribuições eram criar uma revista institucional, auxiliar na criação da Agência IBGE Notícias, desenvolvendo modelos de gráficos e infográficos para essa nova plataforma, e dar suporte aos jornalistas que administram as mídias sociais.

Ao longo dos anos, os designers têm atuado cada vez mais na produção de gráficos diferenciados para as notícias da Agência. Para isso, existe uma rotina em que jornalistas e designers atuam conjuntamente.

Assim, as questões abordadas neste artigo visam discutir esse processo de trabalho entre jornalistas e designers e, principalmente, explicar as motivações das escolhas entre usar gráficos automatizados ou personalizados para acompanhar as notícias.

Essas situações foram investigadas para identificar como se dá o processo de decisão que as delimita. Para isso, foram feitas entrevistas com os jornalistas e designers que atuam diretamente na produção de notícias tomando-se por base teórica a caracterização do design de notícias na idade da comunicação proposta por Moraes Filho (2010).

\section{Coordenação de Comunicação Social (CCS)}

Em 1986, foi criada a Assessoria de Comunicação Social do IBGE, ligada à Presidência do órgão. Entre as suas atribuições, pode-se destacar (Senra, Fonseca, \& Millions, 2018, p.117):

- Prestar assessoramento ao Presidente e ao Diretor-Geral no que se refere à veiculação de informações jornalísticas, para os públicos interno e externo, e, ainda, à gerência do fluxo dessas informações para os veículos de comunicação

- Estabelecer contatos com os meios de comunicação, sempre que necessário;

- Elaborar e encaminhar aos meios de comunicação noticiário de interesse do IBGE;

Na década de 1980, passa a ser chamada de Coordenação de Comunicação Social (CCS), como é conhecida até hoje.

As atribuições da CCS constam na intranet institucional com a seguinte redação: 
A Coordenação de Comunicação Social facilita o fluxo de informações entre o IBGE e a sociedade, por meio dos veículos de comunicação (jornais, revistas, rádios, TVs, sites na Internet). Nosso trabalho visa contribuir para o aperfeiçoamento da comunicação entre o IBGE, seus funcionários e a opinião pública. Traduzindo o texto dos pesquisadores para a linguagem jornalística, agilizamos e complementamos o trabalho dos repórteres. (IBGE, 2020)

\section{Divulgação das pesquisas}

O IBGE produz pesquisas de diversas periodicidades, refletidas no calendário anual de divulgação. O IBGE, através da CCS e de suas diversas áreas de Comunicação, divulga os resultados das pesquisas através de várias plataformas, inclusive no seu próprio portal.

Neste artigo, focamos na divulgação feita pela Agência IBGE Notícias. Seu propósito é divulgar os resultados das pesquisas através dos releases e notícias elaboradas pelos jornalistas e designers da equipe e, para fornecer informação mais completa para seu público (sociedade, mídias regionais e grandes jornais, por exemplo), as notícias são ilustradas com gráficos, que são desenvolvidos de acordo com o tipo de pesquisa, estrutural ou conjuntural.

As estruturais são mais complexas em sua natureza e por isso demandam soluções mais elaboradas. Fonseca (2005) diferencia as pesquisas conjunturais das estruturais, pelo viés da comunicação, de acordo com a dificuldade para divulgá-las:

A compreensão das pesquisas conjunturais, divulgadas mensalmente, se toma mais fácil dentro da rotina de trabalho, segundo os jornalistas. Mas as estruturais (anuais), por serem mais complexas, exigem um esforço maior por parte dos repórteres e editores, como assinala Fonseca (2005):

As pesquisas mais detalhadas exigem um esforço por parte dos repórteres, por parte da coordenação, até para que a gente possa realmente tomar a divulgação interessante, valorizar aquilo que elas trazem de interessante, diz Mauro Silveira, da CBN. (Fonseca, 2005, p.71)

Para as pesquisas conjunturais, o modelo de gráfico utilizado é feito por um sistema automatizado, que utiliza as tabelas do SIDRA (Sistema IBGE de Recuperação Automática). exemplificado pela figura 1.

Já para as pesquisas estruturais, o gráfico é desenvolvido por um designer da equipe, que deve se preocupar com os dados a serem mostrados e elementos de design como tipografia, formato, legibilidade e adaptação para variadas plataformas. A figura 2 exemplifica como o layout é mais complexo que o dos automatizados. 
Figura 1 - Exemplo de gráfico automatizado - IPCA Abril de 2021

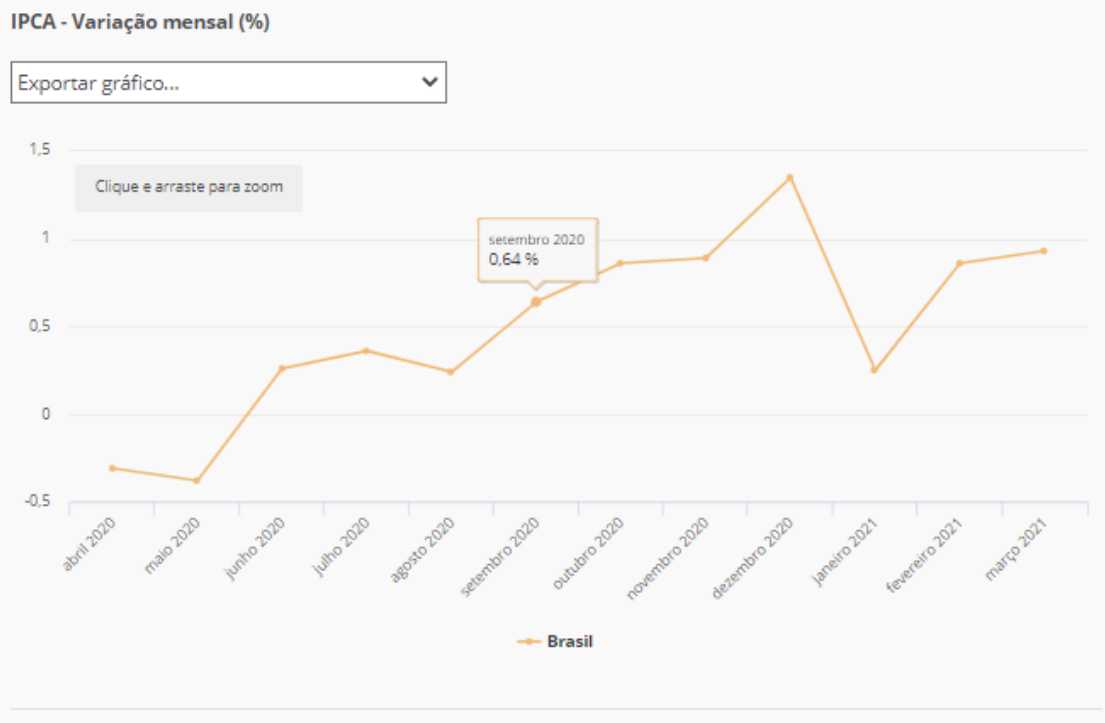

Figura 2 - Exemplo de gráfico criado por designer - Estatísticas de Gênero

Nível de ocupação de pessoas de 25 a 49 anos de idade, com crianças de até 3 anos no domicílio (\%)

Por sexo e cor ou raça

Homens

Mulheres

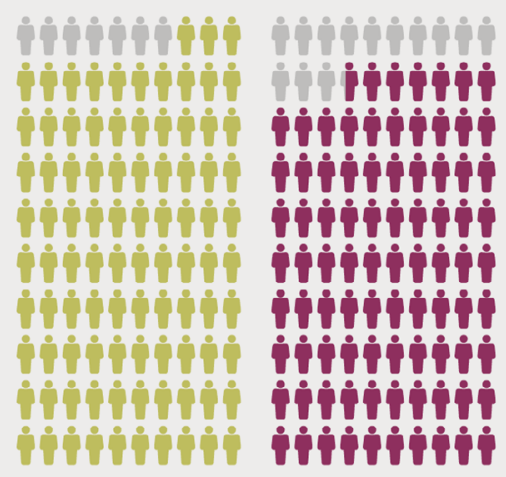

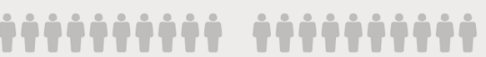

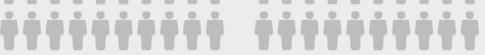

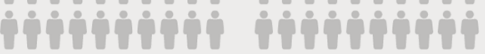

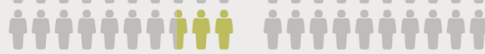

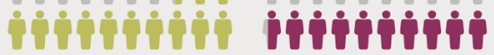

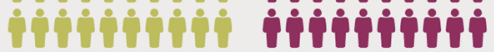

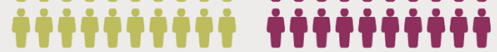

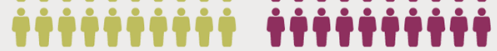

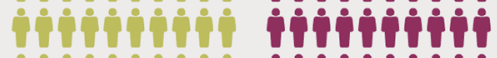

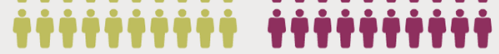

Branca Preta ou parda 


\section{Design de notícias}

Segundo Moraes Filho (2010, p.175) o design de notícias se dá quando a participação do designer ocorre nas etapas decisórias da produção do discurso jornalístico. Sendo anteriormente visto apenas como responsável por estruturar a apresentação visual do objeto jornal, com escolha de tipografia, diagramação e ilustração, era sua responsabilidade a manutenção da identidade visual do jornal. Apesar de ainda haver resquícios dessa visão no cotidiano das redações, em que jornalistas são responsáveis exclusivos pelo conteúdo verbal e designers pela forma visual (Oliveira \& Araújo, 2017), a partir dos anos 1990, o designer assume um novo papel, sendo incorporado ao processo decisório. Isso se deve às mudanças estruturais da sociedade, conforme Moraes Filho (2010, p.81):

Com a expansão das comunicações sociais, o homem comum ficou exposto a um grande volume de informações de naturezas distintas, algumas indispensáveis, outras supérfluas. Ao selecioná-las, para depois analisá-las e oferecê-las contextualizadas aos leitores, os jornais cumpririam o papel de filtro, retendo o que não interessa - o que é discutível - e apresentando de forma organizada, mapeada, aquilo que é relevante- "all the news that fit to print." O designer é decisivo nesse processo ao organizar as informações e apresentá-las da forma mais adequada para esse homem comum, ou nas palavras de Margolin, "(...) torna-se um facilitador da ação social, ajudando a dar forma ao processo de comunicação assim como aos seus produtos."

Ressalta-se assim não só as diferenças entre jornalistas e designers, mas também suas similaridades. Segundo Oliveira e Araújo (2017) há dois pontos em comum: a representação da realidade e o foco no público. Ambos têm desafios no processo de fazer a notícia chegar a seu público, por vias diferentes. Nesse contexto, o designer se torna um mediador entre a notícia e o leitor, levando em conta seu público e a verdade da notícia, devido a sua inerente capacidade de tradução. Essa transformação implica na diferenciação entre design de jornais e design de notícias.

O primeiro termo refere-se ao design aplicado a um determinado objeto, o que lhe impõe limites baseados nas características desse objeto, como a tecnologia de impressão, por exemplo. O segundo relaciona o design ao que seria a "matéria-prima" do jornalismo, o que impõe limitações de ordem distinta: enquanto o primeiro termo está subordinado às contingências de um determinado objeto cultural, o segundo está apto a determiná-las em qualquer objeto relacionado à atividade jornalística.(Moraes Filho, 2010, p.154)

O design de notícias se caracteriza por uma construção de notícias multimodais, ou seja, não totalmente submetidas ao texto. Aumenta a utilização de diagramas e infográficos, e a página de notícia se organiza em torno da forma mais adequada para representar o discurso jornalístico. Essa multiplicação de discursos resulta numa maior participação do designer nas etapas de planejamento e construção de narrativas. 
A metodologia do design de notícias também se diferencia da metodologia do design de jornais. Na figura 3 observa-se como acontece o processo, em que dois caminhos distintos podem ser tomados: o das apostas e o das matérias ordinárias. Enquanto matérias ordinárias são notícias corriqueiras e não exigem grande detalhamento ou não possuem tanta importância, as apostas são as matérias selecionadas pela editoria para maior destaque.

Figura 3 - Processo do design de notícias, adaptado de Moraes Filho (2010, p.172)

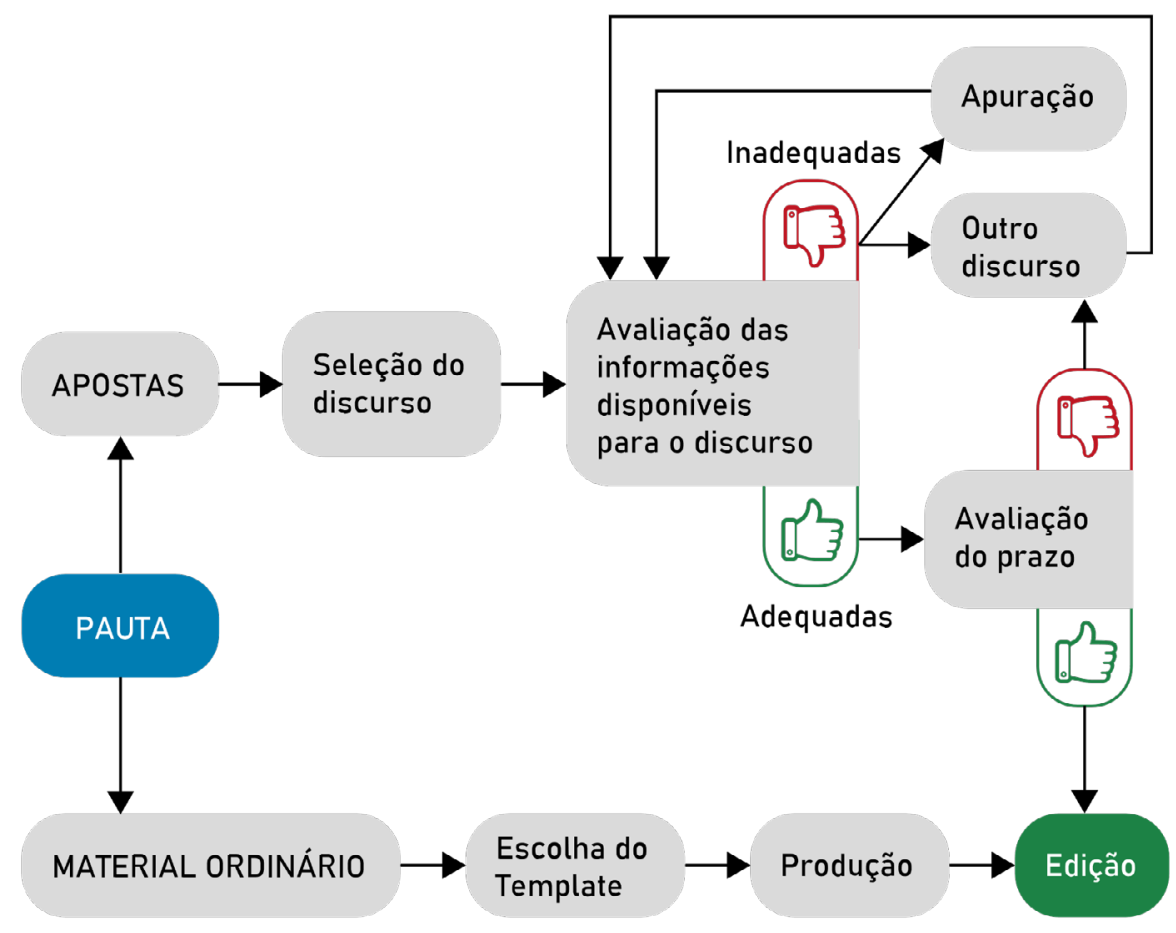

Essa distinção coloca o designer em contato direto com o editor, que tem a função de realizar a seleção entre o que é ordinário e o que é aposta, e nessa relação podem surgir conflitos. Enquanto um tem uma formação fundamentada na centralidade do texto, o outro é tradicionalmente ensinado a compreender sua função apenas através da comunicação visual.

\section{Objetivos}

- Entender como o processo de design de notícias pode ser comparado às práticas de trabalho da Agência IBGE Notícias

- Compreender as causas de diferenças entre o processo de design de notícias e a rotina da Coordenação de Comunicação Social (CCS) do IBGE 


\section{Metodologia}

\section{Entrevista estruturada}

Foi utilizada a metodologia de entrevista estruturada, na qual há uma roteirização da interação entre entrevistador e participante. Definida uma pauta de entrevista, com formulário para recorte e perguntas abertas (Yin, 2016), procedeu-se com a maior uniformidade possível tanto na apresentação das perguntas quanto no local em que foram realizadas. Essa metodologia foi utilizada por propiciar que os entrevistados respondam de forma livre, expondo suas ideias, sem ficarem limitados às opções das perguntas fechadas.

As entrevistas, realizadas em novembro de 2019 , foram gravadas e duraram de 10 a 20 minutos. Introdutoriamente, o entrevistador explicou seus objetivos e apresentou ao entrevistado 2 cópias do termo de consentimento livre e esclarecido para serem assinadas, explicando que esse documento assegura a não-identificação do respondente e o resguarda para emitir quaisquer opiniões sem constrangimento.

A população da CCS é formada por jornalistas, designers e estagiários de jornalismo. Os jornalistas têm diversas atividades, entre elas o atendimento à imprensa, o preparo de releases, a elaboração de notícias para a Agência IBGE Notícias, além de se responsabilizarem pelos hotsites do Censo Agropecuário e do Censo 2020.

Por sua vez, as funções dos designers incluem elaborar imagens e gráficos, escolher fotografias para ilustrar as notícias e reportagens, alimentar a Agência IBGE Notícias através de seu administrador (se preocupando com a formatação dos releases e notícias), atender aos pedidos de elaboração de imagens e vídeos para as redes sociais, além de também serem responsáveis pelos hotsites do Censo Agropecuário e do Censo 2020.

Para a entrevista, a amostra selecionada, constituída por três jornalistas e dois designers, foi a da equipe responsável pela produção diária de material e inserção de notícias na Agência. Segundo Muchielli (1978, p.28) a amostra consiste em identificar, dentre as características da população, aquelas que estiverem logicamente relacionadas aos objetivos da pesquisa, justificando assim esta seleção.

\section{Categorização}

Foi realizada a codificação das respostas, com o propósito de "começar a passar metodicamente para um nível conceitual um pouco mais alto" (Yin, 2016) a informação coletada.

Para Flick (2009, p.291), a análise de conteúdo do material textual têm como uma de suas características mais importantes a categorização, que é um método para agrupar os termos que aparecem com mais frequência e que serão objeto de estudo.

Segundo Fontanella et al. (2011, p.390) "para cada categoria são agrupados os correspondentes temas e tipos de enunciados identificados e consensuados, fazendo constar trechos das entrevistas que os exemplificam". 
Para isso, após a transcrição das respostas, foram marcados os trechos tópicos e representantes do argumento feito pelo entrevistado. A seguir foram verificados quais os pontos em comum encontrados, delimitados e agrupados de acordo com as categorias elaboradas.

\section{Resultados}

\section{Contradição entre designers e jornalistas}

Designers e jornalistas discordam sobre como o processo poderia funcionar, e sobre quais problemas afetam a rotina de trabalho, o que se pode constatar em seus depoimentos:

Designer: "(o jornalista) não sabe passar as coisas pra gente."

Jornalista: "eu acho que essa conversa podia ser mais estreita e da parte do designer ele se inteirar mais da realidade da pesquisa."

Jornalista: “(...)tradicionalmente o jornalista recebe esse material e tem q digerir pra poder chegar aos destaques e tudo mais. Esse trabalho vem cada vez mais sendo feito em parceria, designer com jornalista."

\section{Pesquisas conjunturais são matérias ordinárias}

As pesquisas conjunturais podem ser consideradas matérias ordinárias por serem de periodicidade menor. Seu fluxo de trabalho exige maior agilidade.

Designer: "para as conjunturais, os gráficos interativos são gerados pela plataforma SIDRA."

Jornalista: "como a gente tem uma carga de divulgações muito grande mensal, então optou-se por todos os indicadores conjunturais serem tirados os gráficos que já vem prontos, que são esses interativos do SIDRA."

\section{Pesquisas estruturais são apostas}

Comparadas ao fluxo sugerido por Moraes Filho (2010), as pesquisas estruturais se enquadram como apostas, sua periodicidade é maior. A esse respeito, os profissionais afirmaram nas entrevistas:

Designer: "Os outros gráficos que já são para visualizar os dados são gerados para notícias(...) para contar uma história diferente com mais detalhes, então são usados mais para as pesquisas estruturais."

Jornalista: “(...)para as pesquisas estruturais, como o Censo Agro, as PNADs Contínuas de rendimento, educação, são dados mais interessantes, mais palatáveis que a gente consegue colocar num contexto social também e relacionar de outras formas, a gente consegue e a gente tem mais tempo para pensar sobre isso e pesquisar mais, ver outras formas de visualização de dados(...)" 


\section{Discussão}

A decisão editorial sobre qual gráfico utilizar se dá devido às características específicas de pesquisas estruturais e conjunturais. Estas categorias requerem tratamentos gráficos diferentes, a primeira com a participação ativa do designer, a segunda utilizando-se de gráficos automatizados. A diferença entre pesquisas conjunturais e estruturais é análoga às matérias ordinárias e apostas propostas por Moraes Filho e o processo de decisão editorial segue o descrito pelo autor.

Quanto à ferramenta, os entrevistados demonstraram interesse em um sistema com mais variedade de gráficos, sem sentir dificuldades na utilização do atual. A literatura sugere que quanto mais o designer participa de todo o processo de geração da notícia, mais se torna em consonância com o processo de design de notícias. Os designers ainda veem seu trabalho como no modelo antigo, em que eram parte das etapas finais do processo, subordinados à editoria, sem fazer parte de todo o processo de projeto, incluindo as etapas de discussão inicial, pré-briefing e planejamento.

Por sua vez, os jornalistas esperam maior participação dos designers justamente nessas etapas decisórias.

\section{Conclusões}

Considerando os comentários dos jornalistas sobre a necessidade de maior participação e proatividade dos designers, em contraste com o desejo destes de receber o conteúdo em etapas posteriores de análise, nota-se que os designers ainda seguem formas antigas de trabalho, em que eram parte das etapas finais do processo, subordinados à editoria.

Ao designer, como ator relevante na elaboração de discursos e mediador entre a informação e o leitor, cabe a prerrogativa de assumir para si parte da responsabilidade pela construção da notícia. (Moraes Filho, 2010).

O IBGE busca a multimodalidade, incluindo infográficos e vídeos, mas esse processo poderia ser aperfeiçoado com a participação do designer na construção dos discursos, em especial em pesquisas estruturais. Para isso, tanto jornalistas quanto designers teriam que abrir um diálogo estabelecendo novas formas de trabalho e suprindo eventuais deficiências ou lacunas para a produção de notícias e infográficos, tendo em mente que ambos formam uma unidade.

A aplicação também demonstra como uma metodologia de entrevistas comparativas pode ser utilizada no contexto da cultura institucional para avaliar as diferenças de percepção de designers e jornalistas. Essa metodologia pode ser aplicada em outras instituições, informando o estado atual da cultura em relação ao design de notícias e diferenciando notícias de aposta das ordinárias.

Próximas investigações envolveriam o acompanhamento de medidas para a mudança da cultura institucional, avaliando o impacto da mudança do papel do designer tanto na produção cotidiana quanto nas percepções dos atores envolvidos. 


\section{Agradecimento}

Nossos agradecimentos aos professores André Ribeiro (UERJ/PPDESDI) e André Monat (UERJ/PPDESDI) pelas contribuições no desenvolvimento dessa pesquisa.

Ao IBGE, que apoiou o desenvolvimento dessa pesquisa e aos gerentes e colegas de nossas equipes, GEON e CCS.

\section{Referências}

Flick, U. (2009). Introdução à pesquisa qualitativa. Porto Alegre: Bookman.

Fonseca, S. M. (2005). A notícia da estatística: a divulgação das notícias do IBGE na visão dos jornalistas. Escola Nacional de Ciências Estatísticas.

Fontanella, B. J. B., Luchesi, B. M., Saidel, M. G. B., Ricas, J., Turato, E. R., \& Melo, D. G. (2011). Amostragem em pesquisas qualitativas: proposta de procedimentos para constatar saturação teórica. Cad. Saúde Pùblica, 389-394.

IBGE. (2013). Plano estratégico 2012-2015 (p. 78). p. 78. Rio de Janeiro: IBGE.

Instituto Brasileiro de Geografia e Estatística (n.d.). Disponível em https://www.ibge.gov.br/institucional/o-ibge.html

Moraes Filho, A. P. de. (2010). Design de notícias: um estudo de casos múltiplos.

Mucchielli, R. (1978). O questionário na pesquisa psicossocial. São Paulo: Martins Fontes.

Oliveira, E. A. de, \& Araújo, J. L. (2017). Design de notícias no curso de Jornalismo: uma experiência de ensino a partir do design da informação. InfoDesign - Revista Brasileira de Design Da Informação, 14(2), 204-217.

Senra, N. de C., Fonseca, S. M., \& Millions, T. C. (2018). Brasil em pauta: a trajetória da comunicação no IBGE. Rio de Janeiro: IBGE, Centro de Documentação e Disseminação de Informações.

Yin, R. K. (2016). Pesquisa qualitativa do início ao fim. Porto Alegre: PENSO.

\section{Sobre os autores}

Guilherme da Costa Garcia, Mestrando, ESDI/UERJ, Brasil <atypicalgarcia@gmail.com> Helga Szpiz, Doutoranda, ESDI/UERJ, Brasil <helgaszpiz@gmail.com> 